\title{
Spectrophotometric Determination of Allura Red AC and Tartrazine in Food Products Using Hydrophobic Deep Eutectic Solvents as an Environmentally Sustainable Micro-Extractor
}

\author{
Gabriela R. Piton, ${ }^{a}$ Karen K. L. Augusto, ${ }^{a}$ Daniel Jr. A. Santos ${ }^{a}$ and \\ Orlando Fatibello-Filho ${ }^{\oplus * a}$ \\ ${ }^{a}$ Laboratório de Analítica, Bioanalítica, Biosensores, Eletroanalítica e Sensores, \\ Departamento de Química, Universidade Federal de São Carlos (UFSCar), \\ CP 676, 13560-970 São Carlos-SP, Brazil
}

\begin{abstract}
This paper reports the application of hydrophobic deep eutectic solvents (HDES) as an environmentally friendly alternative for liquid-phase microextraction (LPME) of Allura Red AC and Tartrazine in food products and the spectrophotometric determination of these analytes. The HDES used in this work were prepared by mixing octanoic acid (OctAc) or decanoic acid (DecAc) and tetrabutylammonium bromide (N4444-Br) in a molar ratio of 2:1. An investigation was also carried out regarding the effects of sample $\mathrm{pH}$, sample volume, HDES volume, and concomitants on the analytical performance of the proposed method. The analytical curves obtained for Allura Red AC and Tartrazine in octanoic acid (OctAc)-tetrabutylammonium bromide (N4444-Br) were in the linear concentration ranges of 0.05 to $2.00 \mathrm{mg} \mathrm{L}^{-1}$ and 0.04 to $2.14 \mathrm{mg} \mathrm{L}^{-1}$, with limits of detection of 0.005 and $0.004 \mathrm{mg} \mathrm{L}^{-1}$, respectively. The proposed technique was successfully applied for the determination of Allura Red AC and Tartrazine in food products.
\end{abstract}

Keywords: spectrophotometric determination, Allura Red AC, Tartrazine, hydrophobic deep eutectic solvents (HDES), liquid-phase microextraction (LPME)

\section{Introduction}

Synthetic dyes are widely used as food additives in place of natural dyes; these additives are employed in food products to give them a more attractive appearance, with bright color and good stability, thus impeding the occurrence of variations in the color of the final product. ${ }^{1,2}$ Although the application of synthetic dyes as food additives help improve the attractiveness and stability of the food color, making the food more appealing to consumers, there is strong evidence that high consumption of dyes may cause the development of allergies, asthmatic reactions, cancer, among other diseases. ${ }^{3,4}$ Given that, the use of synthetic dyes in food products is legally controlled by health authorities and national regulatory bodies worldwide. In Brazil, the permission to use and the establishment of a legal tolerable threshold for synthetic food dyes are under the responsibility of ANVISA (the National Agency of Sanitary Surveillance); this agency currently provides legal permission for the use of eleven synthetic dyes.

*e-mail: bello@ufscar.br
Allura Red AC (AR) and Tartrazine (TA) (Figure 1) are commonly used, alone or mixed, in several food products, and based on the legal limit established by ANVISA (under Resolution 387/99), ${ }^{5}$ their content is restricted to $30 \mathrm{mg}$ per $100 \mathrm{~g}$ of the food sample. Considering the risks that synthetic dyes pose to human health and the legal restrictions imposed by health authorities regarding the maximum tolerable limits of these additives in food

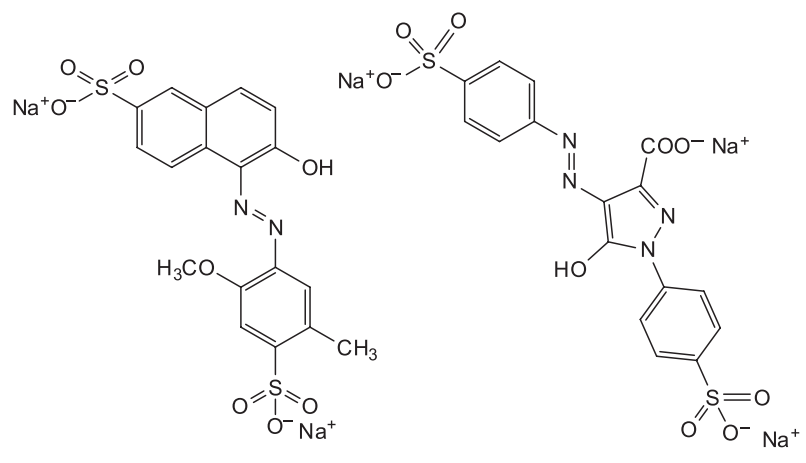

(a)

(b)

Figure 1. Chemical structures of the dyes: (a) Allura Red AC (AR) and (b) Tartrazine (TA). 
products, one does not need to overestimate the importance of developing analytical techniques capable of determining these dyes in foods and helping to control the use of the dyes in commercial products in the food industry.

To conduct an accurate analysis of synthetic dyes in food products, sample pretreatment is usually required owing to the complexity of food products matrices and/or the limitation of the instrumental technique. The liquidliquid extraction (LLE) technique has drawn considerable attention in sample preparation, ${ }^{6-10}$ including the preparation of food samples, especially because the mechanism can be operated easily, in addition to its ability to yield high enrichment factors with short extraction times. Unfortunately, there has been widespread use of toxic, flammable, and environmentally unfriendly hazardous solvents for the conduct of analysis by the LLE technique. Hence, the development of suitable and environmentally friendly solvents for LLE has drawn considerable interest among researchers worldwide. As reported in the literature ${ }^{11}$ suitable solvents for LLE should possess some relevant characteristics such as immiscibility with water, low density, low volatility, high coefficients of partition, and low melting and freezing points. In this context, there has been an increasingly growing interest among researchers regarding the development of novel liquid-liquid extraction techniques which are capable of ensuring high efficiency yet are still in agreement with the principles of green chemistry. ${ }^{12,13}$ Several studies published in the literature ${ }^{14-17}$ have proposed a wide range of LLE techniques using alternative solvents as extractors.

Deep eutectic solvents (DES) are a new generation of ionic liquids (ILs) synthesized from a eutectic mixture of a hydrogen bond acceptor (HBA) and a hydrogen bond donor (HBD) with melting points far below those of the individual components. ${ }^{18}$ The use of DES presents remarkable advantages; these include easy preparation, low cost, low volatility, $100 \%$ atomic efficiency, and good biodegradability.

Recently, hydrophobic deep eutectic solvents (HDES), which are immiscible with water, have been used as an alternative extractive medium for extracting non-polar organic and inorganic compounds from aqueous solutions, replacing most organic solvents of high toxicity. ${ }^{19-21}$ HDES were developed for the first time in $2015 ;{ }^{16}$ the solvents consist of fatty acids and quaternary ammonium salts. Octanoic and decanoic acids are known for their moderate ability to undergo hydrogen-bonding interactions and, due to their high hydrophobic behavior, these acids exhibit good performance as extraction media and display excellent stability when they are in contact with water. In the present work, the two fatty acids, octanoic and decanoic acids
(OctAc and DecAc, respectively), were applied as HBD, and tetrabutylammonium bromide (N4444-Br), which has physical properties similar to choline chloride, was employed as HBA. ${ }^{22}$ Considering that the interest of this work is to evaluate the use of HDES in extractions involving water solutions, the resulting properties of HDES after using two different HBDs are of great interest to the investigation.

Among the physical properties of HDES, water content, density, and volatility are worth mentioning because they provide essential information on whether the solvent will be efficient for extraction. Very few studies published in the literature ${ }^{22-25}$ have investigated the physical-chemical properties of DES/HDES. It is worth noting that when fatty acids are used as HBD, there is a relationship between the physical-chemical properties of the solvents and the alkyl chain length. According to Bonhôte et al., ${ }^{26}$ an increase in the alkyl chain results in stronger van der Walls forces, and, hence, higher viscosity. As in traditional ILs, the water content can exert influence on some physical properties of DES/HDES; furthermore, it can, to a larger extent, undo the hydrogen bond interactions that define a deep eutectic solvent. $^{27}$

Due to their suitable properties, HDES have been widely used as solvent extractors in liquid-liquid micro-extraction techniques. ${ }^{28-30}$ Thus, the present work aims to investigate for the first time the use of HDES, synthesized from OctAc or DecAc acid and tetrabutylammonium bromide (N4444-Br) in a molar ratio of 2:1, for the liquid-phase micro-extraction (LPME) of Allura Red AC and Tartrazine in food products and the spectrophotometric determination of these analytes.

\section{Experimental}

\section{Reagents and standards}

Tetrabutylammonium bromide (N4444-Br, 99\%), Allura Red AC (AR, dye content ca. 80\%) and Tartrazine (TA, dye content ca. 90\%) were purchased from SigmaAldrich Co. Ltd. (St. Louis, MO, USA). Octanoic acid (>98\%) was purchased from Synth (Diadema, SP, Brazil) and decanoic acid $(\geq 98 \%)$ was purchased from Neon (Suzano, SP, Brazil). Ultra-purified water (electric resistivity > $18 \mathrm{M} \Omega \mathrm{cm}$ ) supplied by a Milli-Q system (Millipore) was used in the preparation of all aqueous solutions.

\section{Instrumentation and procedures}

The absorbance measurements were performed using a UV-Vis spectrophotometer (Shimadzu UV-2550) with a 
wavelength range of 300-700 $\mathrm{nm}$, and a quartz cuvette of $700 \mu \mathrm{L}$ with a path length of $10 \mathrm{~mm}$. UV Probe software was used for the acquisition of the spectral data.

Vortex mixer Genius 3 (IKA, China) was used as an auxiliary apparatus for the extraction of synthetic dyes from the aqueous phase to HDES phase. After extraction, an SL-700 centrifuge model (Solab Científica, Brazil) was used to speed up the separation between the two phases.

The water content in the HDES medium was determined by the Karl-Fischer method using an 899 KF Coulometer (Metrohm) with a generator electrode and without diaphragm. A pyridine-free solvent was used in all measurements (Hydranal, Coulometer AG, Honeywell, Brazil). The water content in HDES was determined in triplicate.

\section{HDES synthesis}

The synthesis of HDES was carried out based on a previously reported procedure ${ }^{16}$ which involved mixing the two components (HBD and HBA) in a closed glass with mechanical stirring at $250 \mathrm{rpm}$ and $65^{\circ} \mathrm{C}$ for ca. $3 \mathrm{~h}$ until a homogeneous liquid was formed. Two fatty acids were used as HBD and N4444-Br was employed as HBA. The same molar ratio of 2:1 was used in both synthesis (HBD:HBA) (see Figure S1 in the Supplementary Information (SI)).

\section{Preparation of commercial food sample solutions}

The food samples were purchased in a local market (São Carlos, São Paulo, Brazil). The candy samples were ground to obtain a homogenized powder. A mass of $500 \mathrm{mg}$ of the sample was dissolved in $25 \mathrm{~mL}$ of ultra-purified water. Thereafter, each sample was centrifuged for $10 \mathrm{~min}$ at $5000 \mathrm{rpm}(\mathrm{g}$ force of $3326 \times \mathrm{g})$. For the powder juice samples, a mass of $500 \mathrm{mg}$ was dissolved in $25 \mathrm{~mL}$ of ultrapurified water and centrifuged for $10 \mathrm{~min}$ at $5000 \mathrm{rpm}$. The supernatant of both samples was applied in the proposed technique (see "HDES-based LPME procedure" subsection below).

\section{HDES-based LPME procedure}

To evaluate the extraction efficiency of the proposed HDES, an LPME technique for food dyes was developed. Standard solutions of $1.0 \mathrm{mmol} \mathrm{L}^{-1} \mathrm{AR}$ and $1.0 \mathrm{mmol} \mathrm{L}^{-1} \mathrm{TA}$ in water were prepared and used for subsequent dilutions of working solutions. For extraction, an accurate volume of $15.0 \mathrm{~mL}$ aqueous solution was placed in a $20 \mathrm{~mL}$ centrifuge tube and $1.0 \mathrm{~mL}$ of HDES was added. The mixture was subjected to vortex mixing for $60 \mathrm{~s}$ at room temperature $\left(25 \pm 1{ }^{\circ} \mathrm{C}\right)$. Centrifugation for $10 \mathrm{~min}$ at $5000 \mathrm{rpm}$ allowed the separation of the phases. The absorbance of the HDES-rich phase $(\lambda(\mathrm{AR})=506 \mathrm{~nm}$ and $\lambda(\mathrm{TA})=426 \mathrm{~nm})$ was measured directly with no further dilution (see UV-Vis spectra in Figure S3, SI section). Photos of the solutions before and after extraction (including the HDES-phase) are presented in the Supplementary Information (Figure S2).

\section{Results and Discussion}

HDES selection for LPME and salting-out effect

The selection of HDES for LPME is one of the key procedures that determine the success or failure of the extraction process. To obtain good extraction performance, the HDES is required to have a good affinity for each analyte in the sample. As a second condition, after the extraction step, HDES/water should present two-phases separation; and, as a final condition, the HDES phase containing the extracted analytes should be suitable for direct spectrophotometric measurement without the need for any modification or reagent addition. Thus, to examine the extraction efficiency of the HDES, two different fatty acids were employed for the preparation of the solvents. OctAc and DecAc (employed as HBD) and N4444-Br (employed as HBA) in a molar ratio of 2:1 were investigated to evaluate the effects of alkyl chain length of the acids on the extraction of both synthetic dyes. To perform this analysis, the HDES and the sample aqueous solutions were mixed in a ratio of 1:10 (v/v) for $60 \mathrm{~s}$ (see "Effect of vortex time" sub-section) with the aid of a vortex mixer. As the DecAc-N4444-Br HDES presented a jelly phase, the spectrophotometric measurement of the extracted analyte was impaired. In order to promote a good separation between the phases, an investigation was carried out regarding the addition of $\mathrm{NaCl}$ in the aqueous phase using the following final concentrations 0 (without $\mathrm{NaCl}$ ), 5, 10, 15 , and $20 \% \mathrm{~m} / \mathrm{v}$. The efficiency of the salting-out effect was evaluated using spectrophotometric measurements of the HDES-rich phase for $2.5 \mathrm{mg} \mathrm{L}^{-1}$ aqueous solutions of each analyte. For $\mathrm{NaCl}$ concentrations less than $10 \% \mathrm{~m} / \mathrm{v}$, the jellification undermined the spectrophotometric determination of the extracted analyte. On the other hand, for $\mathrm{NaCl}$ concentrations ranging from 10 to $20 \% \mathrm{~m} / \mathrm{v}$, both analytes were determined with great accuracy and precision. The extraction efficiency for $\mathrm{NaCl}$ in the range of 10 to $20 \% \mathrm{~m} / \mathrm{v}$ was practically the same. Although salt addition can improve extraction efficiency, at higher concentrations, it may lead to an increase in the aqueous phase viscosity, which decreases the mass transfer process from aqueous to HDES medium. ${ }^{31}$ 
Table 1. Physical-chemical properties of the studied HDES, including water content, density and melting point

\begin{tabular}{|c|c|c|c|c|c|c|c|}
\hline \multirow{2}{*}{ HDES } & \multirow{2}{*}{ HBD } & \multirow{2}{*}{ HBA } & \multirow{2}{*}{ Molar ratio } & \multicolumn{2}{|c|}{ Water content ${ }^{\mathrm{a}} / \mathrm{wt} . \%$} & \multirow{2}{*}{$\begin{array}{c}\text { Density }{ }^{\mathrm{b}} / \\
\left(\mathrm{kg} \mathrm{m}^{-3}\right)\end{array}$} & \multirow{2}{*}{$\begin{array}{c}\text { Melting } \\
\text { point } t^{\mathrm{b}} /{ }^{\circ} \mathrm{C}\end{array}$} \\
\hline & & & & Before extraction & After extraction & & \\
\hline HDES 1 & DecAc & N4444-Br & $2: 1$ & $0.39 \pm 0.03$ & $5.71 \pm 0.09^{c}$ & 957 & 16.17 \\
\hline \multirow{2}{*}{ HDES 2} & \multirow{2}{*}{ OctAc } & \multirow{2}{*}{ N4444-Br } & \multirow{2}{*}{$2: 1$} & \multirow{2}{*}{$0.88 \pm 0.02$} & $4.91 \pm 0.05^{\mathrm{c}}$ & 974 & 0.58 \\
\hline & & & & & $6.67 \pm 0.09$ & 974 & 0.58 \\
\hline
\end{tabular}

${ }^{\mathrm{a}} \mathrm{n}=3$; ${ }^{\mathrm{b}}$ data from reference $32 ;{ }^{\mathrm{c}}$ with $10 \% \mathrm{~m} / \mathrm{v} \mathrm{NaCl}$ solution. HDES: hydrophobic deep eutectic solvent; HBD: hydrogen bond donor; HBA: hydrogen bond acceptor; DecAc: decanoic acid; N4444-Br: tetrabutylammonium bromide; OctAc: octanoic acid.

Considering that the OctAc-based HDES presented no jellification, the salting-out effect was investigated using $\mathrm{NaCl}$ concentration in the range of 0 to $20 \% \mathrm{~m} / \mathrm{v}$ with both analytes at a concentration of $2.5 \mathrm{mg} \mathrm{L}^{-1}$. The results obtained showed no significant improvement in extraction efficiency for the $\mathrm{NaCl}$ concentration range evaluated. By virtue of that, OctAc-based HDES was selected as an extractor without the use of $\mathrm{NaCl}$ in aqueous solution.

The water content (wt.\%) in HDES medium before and after the extraction of both analytes at a concentration of $2.5 \mathrm{mg} \mathrm{L}^{-1}$ was determined by the Karl-Fischer method in triplicate $(\mathrm{n}=3)$, as described in "Instrumentation and procedures" sub-section. For the DecAc-N4444-Br HDES (HDES 1), a $10 \% \mathrm{~m} / \mathrm{v} \mathrm{NaCl}$ was employed in the extraction process; and for OctAc-N4444-Br HDES (HDES 2), two aqueous solutions were used with and without $10 \% \mathrm{~m} / \mathrm{v}$ $\mathrm{NaCl}$. The HDES 1 presented a water content of 0.39 and $5.71 \%$ before and after extraction, respectively. HDES 2, before extraction, presented a water content of $0.88 \%$; after extraction with a $10 \% \mathrm{~m} / \mathrm{v} \mathrm{NaCl}$ the water content was $4.91 \%$ and without $\mathrm{NaCl}$ was $6.67 \%$. Additional physicalchemical properties of the HDES, including the molar ratio of HBD and HBA, density, and melting points, are presented in Table 1. As the density of both HDES is lower than that of water solution, this facilitates the transfer of the HDES-phase to the spectrophotometric cuvette, thus simplifying the proposed method. Moreover, an increase in the water content in the eutectic solvent decreases its viscosity which increases mass transfer and/or extraction efficiency as discussed by Dai et al. ${ }^{33}$ collaborating with the results obtained in this work. The water content of HDES 2 is higher than that of HDES 1, which facilitated the extraction of both dyes. In the development of liquidliquid extraction procedures, the viscosity of the extractor solvent is also of great interest since high viscous solvents hinder the mass transference process. An increase in the alkyl chain of the organic acid, for the same $\mathrm{HBA}^{32}$ an increase in the viscosity is observed, thus agreeing with the results obtained in this work.

\section{Study of volume ratio}

An investigation was also conducted regarding the effects of six different volume ratios of HDES:aqueous solution $(1: 1,1: 3,1: 5,1: 10,1: 15,1: 20,1: 25 \mathrm{v} / \mathrm{v})$ on the extraction of $1.0 \mathrm{mg} \mathrm{L}^{-1} \mathrm{AR}$. The HDES (OctAc-N4444-Br in a molar ratio of 2:1) volume was kept at $1.0 \mathrm{~mL}$, vortex time at $60 \mathrm{~s}$ (see "Effect of vortex time" sub-section), and temperature at $25 \pm 1{ }^{\circ} \mathrm{C}$. Figure 2 shows that maximum extraction efficiency was observed for the following volume ratios: 1:15 and 1:20. Thus, for higher volume ratios the extraction efficiency decreases. In this sense, the volume ratio of 1:15 was selected for further experiments. Similar results were found for the extraction of TA under the same experimental conditions (not shown).

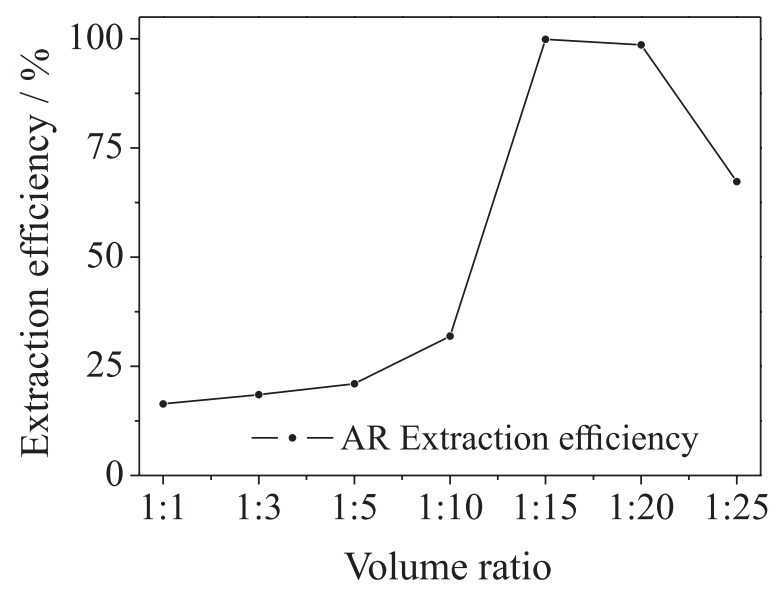

Figure 2. Effect of volume ratio on the extraction efficiency of Allura Red AC food dye using a $1.0 \mathrm{mg} \mathrm{L}^{-1}$ standard aqueous solution and $\mathrm{n}=3$.

\section{Effect of $\mathrm{pH}$}

The effect of hydrogen concentration $(\mathrm{pH})$ in the range of 2.0 to 9.0 on the micro-extraction of $1.0 \mathrm{mg} \mathrm{L}^{-1} \mathrm{AR}$ and TA aqueous solution was investigated, as described in "HDES-based LPME procedure" sub-section. The results obtained are shown in Figure 3. As can be observed in Figure 3, a maximum extraction efficiency 
for Allura Red AC and Tartrazine was obtained at $\mathrm{pH}$ of 6.5. As a result, the $\mathrm{pH}$ of 6.5 was chosen for all further experiments. The effect of the aqueous solution's $\mathrm{pH}$ in the extraction procedures is considered of major importance. Taking into account the $\mathrm{p} K_{\mathrm{a}}$ of target analytes $\left(\mathrm{p} K_{\mathrm{a}}(\mathrm{AR})=11.4\right.$ and $\left.\mathrm{p} K_{\mathrm{a}}(\mathrm{TA})=9.4\right)$ and that at $\mathrm{pH}$ of 11.4 and $9.4,50 \%$ of these dyes are protonated, respectively, the decrease of extraction of both analytes may be related to the partial deprotonation of carboxylate group for $\mathrm{TA}$ and phenol group for AR. At pH 6.5 the extraction efficiency is higher and decreases at lower pHs. At lower $\mathrm{pH}$, the higher hydrogen cation concentration $\left(\mathrm{H}^{+}\right)$may be interacting with the bromide of N4444-Br employed as HBA and decreasing the hydrogen bond between OctAc and N4444-Br.

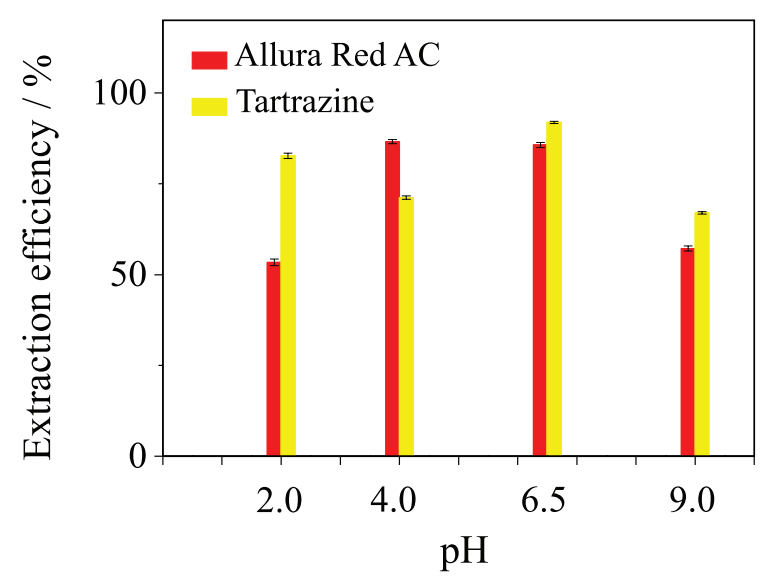

Figure 3. Effect of $\mathrm{pH}$ sample on the extraction efficiency of Allura Red AC and Tartrazine food dyes using $1.0 \mathrm{mg} \mathrm{L}^{-1}$ standard aqueous solutions and $\mathrm{n}=3$.

\section{Effect of vortex time}

The time required to reach extraction equilibrium is highly important for the enhancement of the interaction between the sample solution and the solvent, as well as for the improvement of the mass transfer. ${ }^{34}$ Thus, an investigation was carried out regarding the effect of vortex time in the range of $30-180 \mathrm{~s}$ on the extraction of $1.0 \mathrm{mg} \mathrm{L}^{-1}$ TA and $1.0 \mathrm{mg} \mathrm{L}^{-1} \mathrm{RA}$ using OctAc-N4444-Br in a molar ratio of $2: 1$ and under the temperature of $25 \pm 1{ }^{\circ} \mathrm{C}$. The results are shown in Figure 4. As can be observed, the equilibrium of extraction (maximum extraction efficiency) was reached in $30 \mathrm{~s}$, and it remained constant up to $120 \mathrm{~s}$, decreasing in longer times. A relatively shorter period of time was required to reach equilibrium extraction because of the low solubility of the HDES in water and the high solubility of each analyte in the HDES employed. Bearing this in mind, the vortex time of $60 \mathrm{~s}$ was selected.

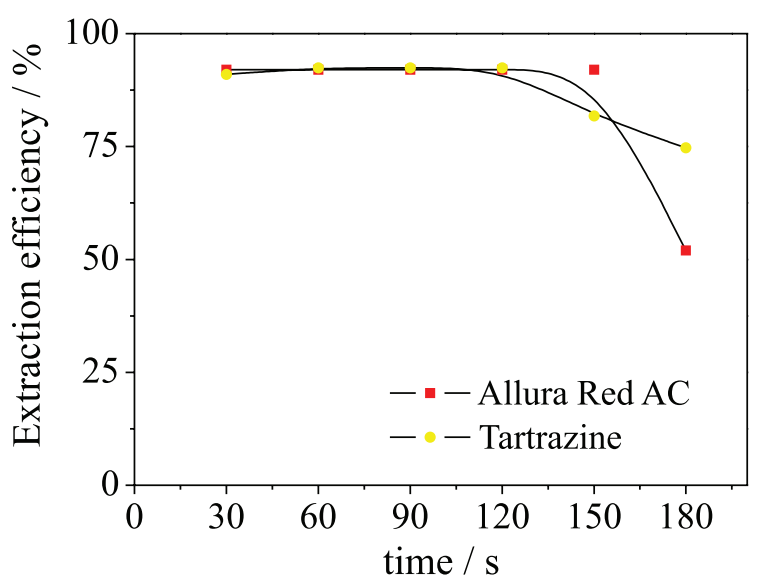

Figure 4. Effect of vortex time on the extraction efficiency of Allura Red AC and Tartrazine food dyes using $1.0 \mathrm{mg} \mathrm{L}^{-1}$ standard aqueous solutions and $\mathrm{n}=3$.

\section{Concomitant effect}

The selectivity of the proposed LPME technique was investigated by the addition of potential interferents (ascorbic acid, citric acid, aspartame, sodium cyclamate, sodium saccharin, zinc sulfate) to a standard solution containing Allura Red AC and Tartrazine in the concentration ratios (standard solution:interferent) of 10:1, 1:1, and 1:10. A comparison was made regarding the concentration of each analyte in the absence and presence of potential interferents. The errors obtained were less than $10 \%$, which indicates that the interferents played no significant role in the determination of the analytes (Allura Red AC and Tartrazine).

\section{Analytical performance}

Under the chosen optimum experimental conditions and through the application of OctAc-based HDES, the analytical curves obtained for Allura Red AC and Tartrazine were in the linear concentration ranges of 0.05 to $2.00 \mathrm{mg} \mathrm{L}^{-1}$ and 0.04 to $2.14 \mathrm{mg} \mathrm{L}^{-1}$, with limits of detection (LOD) of 0.005 and $0.004 \mathrm{mg} \mathrm{L}^{-1}$, respectively. LODs were calculated based on the following equation: $3 \mathrm{sb} / \mathrm{m}$, where $\mathrm{sb}$ is the standard deviation of 10 blank solutions and $\mathrm{m}$ stands for sensitivity. The corresponding analytical equations are as follows (equations 1 and 2):

Absorbance $=(0.01 \pm 0.01)+(0.83 \pm 0.03)\left([\mathrm{AR}] /\left(\mathrm{mg} \mathrm{L}^{-1}\right)\right)$ $\left(\mathrm{R}^{2}=0.995\right)$

Absorbance $=(-0.04 \pm 0.01)+(1.3 \pm 0.1)\left([\mathrm{TA}] /\left(\mathrm{mg} \mathrm{L}^{-1}\right)\right)$ $\left(\mathrm{R}^{2}=0.998\right)$

where $\mathrm{R}^{2}$ is the coefficient of determination.

The analytical curves for both analytes (absorbance versus concentration) in mol L-1 were also constructed 
in order to obtain the respective molar absorption coefficients $\left(\varepsilon\right.$ ) (in $\mathrm{L} \mathrm{mol}^{-1} \mathrm{~cm}^{-1}$ ). The calculated $\varepsilon$ for AR and TA in aqueous solutions (A) and in HDES were, respectively: $2.19 \times 10^{4}(\mathrm{~A})$ and $4.12 \times 10^{5}(\mathrm{HDES})$ and $2.76 \times 10^{4}(\mathrm{~A})$ and $7.11 \times 10^{5}$ (HDES). As expected, the sensitivity of the analytical method was found to be relatively higher in the HDES medium with an increase by a factor of 18.8 and 25.8 for AR and TA, respectively.

To evaluate the intra-day and inter-day repeatability of the proposed extraction technique, studies were performed under optimized conditions. To conduct this analysis, six different Allura Red AC and Tartrazine solutions at concentrations of $2.5 \mathrm{mg} \mathrm{L}^{-1}$ were prepared, followed by independent measurements. The proposed method demonstrated good repeatability with relative standard deviation $(\mathrm{RSD}) \leq 5.0 \%$.

\section{Food samples analysis}

Under optimized conditions, the proposed method was employed for the determination of AR and TA in different food products. To perform this analysis, the concentrations were determined by interpolation using the respective analytical curves, see equations 1 and 2 (see Figure S4, SI section). The proposed HDES-LPME method was compared with a spectrophotometric method for aqueous solutions for both analytes; the results are presented in Table 2. With the application of the paired $t$-test based on the results obtained from the proposed method and the spectrophotometric method used for comparison, the calculated $t_{\exp }$ values (1.524 for AR and 1.196 for TA) were found to be smaller than the $t_{\text {critical }}$ (12.7) at a confidence level of 95\%; this shows that there is no significant difference between the two methods compared. As can be observed from Table 2, the power juice 2 sample presented a higher content of AR than allowed by ANVISA, which is restricted to $30 \mathrm{mg}$ per $100 \mathrm{~g}$ of the food sample.

The linear range and the LOD values obtained by the proposed method were compared with those obtained by the few methods reported in the literature; one will notice that only one of the methods reported in the literature ${ }^{35}$ was applied for the simultaneous determination of AR and TA, see Table 3. The comparative analysis of the method proposed here and the methods reported in the literature ${ }^{35-41}$ showed that the novel HDES-LPME method proposed in this work, which is based on the use of hydrophobic deep eutectic solvent, presented an excellent analytical performance, with better or similar linear range amplitude and significantly lower LOD values compared to the methods reported in the literature. Another shortcoming of the methods reported in the literature ${ }^{35-41}$ and which deserves being mentioned is that some of the methods employ organic solvents such as methanol, tetrahydrofuran (THF), acetonitrile, and octanol during the process; these solvents are considered toxic to the operator and the environment. Furthermore, some of these methods are highly costly to be performed, and this makes them less attractive compared to the proposed method.

\section{Conclusions}

The use of HDES as a solvent extractor in liquidphase micro-extraction (LPME) of analytes has drawn considerable attention among researchers due to the excellent properties of HDES. The present work reported the development of two HDES, synthesized from octanoic acid or decanoic acid and tetrabutylammonium bromide (N4444-Br) (in the molar ratio of 2:1), which were employed toward the micro-extraction of Allura Red AC and Tartrazine in food samples. The OctAc and N4444-Br in the molar ratio of 2:1 were chosen for the LPME analysis. The results obtained in the study showed that the proposed method presents a high pre-concentration factor with high sensitivity, good linearity of the analytical curve for each analyte, good precision, low limits of detection, and satisfactory recoveries. These outstanding properties make the proposed method suitable for the determination of Allura Red AC and Tartrazine in food products.

Table 2. Results obtained in the determination of Allura Red AC (AR) and Tartrazine (TA) in food products using a spectrophotometric and the proposed HDES-LPME methods

\begin{tabular}{lccc}
\hline Sample & Spectrophotometric ${ }^{\mathrm{a}} /(\mathrm{mg}$ per $100 \mathrm{~g})$ & HDES-LPME $^{\mathrm{a}} /(\mathrm{mg}$ per 100 g) & Error $^{\mathrm{b}} / \%$ \\
\hline Powder juice 1 (TA) & $8.82 \pm 0.03$ & $8.77 \pm 0.01$ & -0.57 \\
Powder juice 2 (AR) & $60.1 \pm 0.2$ & $60.2 \pm 0.1$ & +0.17 \\
Candy 1 (AR) & $4.64 \pm 0.02$ & $4.10 \pm 0.03$ & -13 \\
Candy 2 (TA) & $9.89 \pm 0.03$ & $9.33 \pm 0.02$ & -6.0 \\
\hline
\end{tabular}

${ }^{a} \mathrm{n}=3$; ${ }^{\text {berror }}(\%)=[($ HDES-LPME value - spectrophotometric value $) /$ HDES-LPME value $] \times 100$. HDES-LPME: hydrophobic deep eutectic solvent liquid-phase microextraction; TA: Tartrazine; AR: Allura Red AC. 
Table 3. Comparison of the proposed method with other published methods for AR and TA determination

\begin{tabular}{|c|c|c|c|c|c|c|}
\hline \multirow{2}{*}{ Method } & \multirow{2}{*}{ Sample } & \multicolumn{2}{|c|}{$\mathrm{LOD} /\left(\mathrm{mg} \mathrm{L}^{-1}\right)$} & \multicolumn{2}{|c|}{ Linear range / $\left(\mathrm{mg} \mathrm{L}^{-1}\right)$} & \multirow{2}{*}{ Reference } \\
\hline & & $\mathrm{AR}$ & TA & $\mathrm{AR}$ & TA & \\
\hline $\begin{array}{l}\text { Deep eutectic solvent microextraction/ } \\
\text { UV-Vis }\end{array}$ & $\begin{array}{l}\text { water, drug and } \\
\text { beverages }\end{array}$ & - & 0.084 & - & $0.25-2.60$ & 36 \\
\hline VA-DES-DLLME/HPLC & $\begin{array}{l}\text { cherry jelly, } \\
\text { carbonated beverage } \\
\text { and chocolate dragee }\end{array}$ & 0.00003 & - & $0.0005-0.5$ & - & 37 \\
\hline IEME/HPLC-UV & $\begin{array}{l}\text { frizzy drink, fruit } \\
\text { juice, black tea and } \\
\text { fruit jelly powders }\end{array}$ & 0.001 & - & $0.005-0.8$ & - & 38 \\
\hline $\begin{array}{l}\text { Deep eutectic solvent-based microextraction/ } \\
\text { UV-Vis }\end{array}$ & $\begin{array}{l}\text { water, detergent and } \\
\text { chocolate samples }\end{array}$ & 0.0039 & - & $0.5-2.0$ & - & 39 \\
\hline $\mathrm{MOF} / \mathrm{UV}-\mathrm{Vis}$ & $\begin{array}{c}\text { chewing gums, } \\
\text { icing glaze, food } \\
\text { supplementary and } \\
\text { jelly }\end{array}$ & - & 0.0116 & - & $0.5-50$ & 40 \\
\hline Cloud point extraction/UV-Vis & $\begin{array}{l}\text { candy, soft drink and } \\
\text { jellies }\end{array}$ & 0.0078 & - & $0.02-1.4$ & - & 35 \\
\hline Digital image analysis/PLS & food samples & 0.6 & 1.8 & $2.0-26.0$ & $6.0-40.0$ & 41 \\
\hline HDES-LPME/UV-Vis & $\begin{array}{l}\text { powder juice and } \\
\text { candies }\end{array}$ & 0.005 & 0.004 & $0.05-2.00$ & $0.04-2.14$ & this method \\
\hline
\end{tabular}

LOD: limit of detection; AR: Allura Red AC; TA: Tartrazine; UV-Vis: ultraviolet-visible; VA-DES-DLLME: vortex assisted deep eutectic solvent dispersive liquid-liquid microextraction; HPLC: high-performance liquid chromatography; IEME: in-tube electro-membrane extraction; MOF: metal-organic framework; PLS: partial least squares; HDES-LPME: hydrophobic deep eutectic solvent liquid-phase microextraction.

\section{Supplementary Information}

Supplementary data are available free of charge at http://jbcs.sbq.org.br as PDF file.

\section{Acknowledgments}

The authors gratefully acknowledge the financial support granted by the Brazilian research funding agencies including CNPq (process number 405546/2018-1), FAPESP (process No. 2020/01050-5), and CAPES. Both Gabriela R. Piton (CAPES/PROEX No. 8888.2.332753/2019-01) and Karen K. L. Augusto (CAPES/PROEX No. 8888.7.342301/2019-00) are grateful for the MSc scholarships they were offered in the course of this research. This study was partly funded by the Coordenação de Aperfeiçoamento de Pessoal de Nível Superior, Brazil (CAPES), finance code 001. The authors would also like to thank the Chemistry Department at UFSCar for helping with the Karl-Fischer analysis through their analytical center.

\section{References}

1. Feng, F.; Zhao, Y.; Yong, W.; Sun, L.; Jiang, G.; Chu, X.; J. Chromatogr. B 2011, 879, 1813.
2. Deroco, P. B.; Medeiros, R. A.; Rocha-Filho, R. C.; FatibelloFilho, O.; Food Chem. 2018, 247, 66.

3. Amchova, P.; Kotolova, H.; Ruda-Kucerova, J.; Regul. Toxicol. Pharmacol. 2015, 73, 914.

4. Al-Degs, Y. S.; Food Chem. 2009, 117, 485.

5. Agência Nacional de Vigilância Sanitária (ANVISA); Resolução No. 387, de 5 de agosto de 1999; Ministério da Saúde: Brasília, Brazil, 1999; available at http://bvsms.saude. gov.br/bvs/saudelegis/anvisa/1999/res0387_05_08_1999.html, accessed in October 2020.

6. Ahmar, H.; Shahvandi, S. K.; Electroanalysis 2019, 31, 1238.

7. Moura, H. S. R. P.; Rocha, P. R. S.; Amato, A. A.; Sodré, F. F.; Microchem. J. 2020, 152, 104347.

8. Diuzheva, A.; Balogh, J.; Studenyak, Y.; Cziáky, Z.; Jekő, J.; Talanta 2019, 194, 446.

9. Ali, J.; Tuzen, M.; Kazi, T. G.; Food Anal. Methods 2019, 12, 1298.

10. Unsal, Y. E.; Tuzen, M.; Soylak, M.; J. AOAC Int. 2019, 102, 217.

11. Yousefi, S. M.; Shemirani, F.; Ghorbanian, S. A.; Chromatographia 2018, 81, 1201.

12. de la Guardia, M.; Armenta, S. In Comprehensive Analytical Chemistry, vol. 57; de la Guardia, M.; Armenta, S., eds.; Elsevier: Amsterdam, 2011, p. 1-23. 
13. Płotka-Wasylka, J.; Namieśnik, J.; Green Analytical Chemistry: Past, Present and Perspectives; Springer: Singapore, 2019.

14. Gharehbaghi, M.; Shemirani, F.; Food Chem. Toxicol. 2011, 49, 423.

15. Tang, W.; Dai, Y.; Row, K. H.; Anal. Bioanal. Chem. 2018, 410, 7325 .

16. van Osch, D. J. G. P.; Zubeir, L. F.; van den Bruinhorst, A.; Rocha, M. A. A.; Kroon, M. C.; Green Chem. 2015, 17, 4518.

17. Memon, Z. M.; Yilmaz, E.; Soylak, M.; J. Mol. Liq. 2017, 229, 459.

18. Smith, E. L.; Abbott, A. P.; Ryder, K. S.; Chem. Rev. 2014, 114, 11060 .

19. Ribeiro, B. D.; Florindo, C.; Iff, L. C.; Coelho, M. A. Z.; Marrucho, I. M.; ACS Sustainable Chem. Eng. 2015, 3, 2469.

20. Sas, O. G.; Castro, M.; Domínguez, Á.; González, B.; Sep. Purif. Technol. 2019, 227, 115703.

21. Tereshatov, E. E.; Boltoeva, M. Y.; Folden, C. M.; Green Chem. 2016, 18, 4616.

22. Yusof, R.; Abdulmalek, E.; Sirat, K.; Rahman, M. B. A.; Molecules 2014, 19, 8011.

23. Gabriele, F.; Chiarini, M.; Germani, R.; Tiecco, M.; Spreti, N.; J. Mol. Liq. 2019, 291, 111301.

24. Ibrahim, R. K.; Hayyan, M.; AlSaadi, M. A.; Ibrahim, S.; Hayyan, A.; Hashim, M. A.; J. Mol. Liq. 2019, 276, 794.

25. Ruggeri, S.; Poletti, F.; Zanardi, C.; Pigani, L.; Zanfrognini, B.; Corsi, E.; Dossi, N.; Salomäki, M.; Kivelä, H.; Lukkari, J.; Terzi, F.; Electrochim. Acta 2019, 295, 124.

26. Bonhôte, P.; Dias, A.-P.; Armand, M.; Papageorgiou, N.; Kalyanasundaram, K.; Grätzel, M.; Inorg. Chem. 1998, 37, 166.

27. Farias, F. O.; Pereira, J. F. B.; Coutinho, J. A. P.; Igarashi-Mafra, L.; Mafra, M. R.; Fluid Phase Equilib. 2020, 503, 112319.
28. Liu, X.; Liu, C.; Qian, H.; Qu, Y.; Zhang, S.; Lu, R.; Gao, H.; Zhou, W.; Microchem. J. 2019, 146, 614.

29. van Osch, D. J. G. P.; Parmentier, D.; Dietz, C. H. J. T.; van den Bruinhorst, A.; Tuinier, R.; Kroon, M. C.; Chem. Commun. 2016, 52, 11987.

30. Ge, D.; Wang, Y.; Jiang, Q.; Dai, E.; J. Braz. Chem. Soc. 2019, 30, 1203 .

31. Tighrine, A.; Amir, Y.; Alfaro, P.; Mamou, M.; Nerín, C.; Food Chem. 2019, 277, 586.

32. Makoś, P.; Słupek, E.; Gębicki, J.; Microchem. J. 2020, 152, 104384

33. Dai, Y.; Witkamp, G. J.; Verpoorte, R.; Choi, Y. H.; Food Chem. 2015, 187, 14.

34. Gu, T.; Zhang, M.; Tan, T.; Chen, J.; Li, Z.; Zhang, Q.; Qiu, H.; Chem. Commun. 2014, 50, 11749.

35. Pourreza, N.; Rastegarzadeh, S.; Larki, A.; Food Chem. 2011, 126, 1465.

36. Soylak, M.; Uzcan, F.; J. Iran. Chem. Soc. 2020, 17, 461.

37. Faraji, M.; J. Chromatogr. A 2019, 1591, 15.

38. Bazregar, M.; Rajabi, M.; Yamini, Y.; Asghari, A.; J. Chromatogr. A 2015, 1410, 35.

39. Uzcan, F.; Soylak, M.; Int. J. Environ. Anal. Chem. 2020, DOI 10.1080/03067319.2020.1738422.

40. Oymak, T.; Tokalığlu, Ş.; Cam, Ş.; Demir, S.; Food Addit. Contam. 2020, 37, 731.

41. Vidal, M.; Garcia-Arrona, R.; Bordagaray, A.; Ostra, M.; Albizu, G.; Talanta 2018, 184, 58.

Submitted: July 9, 2020

Published online: October 26, 2020 